\title{
Simulation of Earthquake Response of High-rise Structure
}

\author{
ZHAO Yun ${ }^{1, a}$, WEI Hua ${ }^{1, b}$, WANG Haijun ${ }^{1, c}$ \\ ${ }^{1}$ College of Architectural Engineering, Shenyang University of Technology, Shenyang, Liaoning, \\ 110870, China \\ a great20102001@yahoo.com.cn, ${ }^{\mathrm{b}}$ weiflower1973@yahoo.com.cn, ${ }^{\mathrm{c}}$ corresponding author: \\ wang_navy@hotmail.com
}

Keywords: simulation, high-rise structure, dynamic response

\begin{abstract}
It has been proved by more and more practices that the simulation technique (ST) can get a more satisfied result than experiments in some cases like large-span or high-raise structures. Herein, the ST is applied to simulating the earthquake response of a high building on a rigid-foundation based on the SIMUSHIS (Multimedia Simulation System of Seism-induced High-rise Structure) which is developed in ANSYS Workbench. In this paper, the simulation analysis method for high-raise structures, combined with technology of the real-time dynamic display, will be set up to analyze the earthquake response of structures.
\end{abstract}

\section{Introduction}

Many kinds of analytical methods, such as the pseudo-static method, response spectrum analysis, and time-history analysis and so on, have been founded to analyze the earthquake response.

Many programs are designed to research the modality of deformation, damage and collapse of structures which is a very complicated random process[1]. Large of financial and material capabilities and human resources will be used up when full-scale tests are implemented.

Therefore, a reduced-scale test structure is constructed to simulate a large scale structure, and accordingly one computation model is set up to analyze the earthquake response of one reality building based on time-history analysis. By means of the three-dimensional animation, the type of deformation, damage and collapse will be acquainted visually and clearly, and mass data processing can be unnecessary. Emulation techniques such as the ADAMS and the SIMUSHIS are gradually being applied to civil engineering [2].

\section{Outline of the Method for Simulation Analysis}

With the development of high-rise buildings, the height increases continuously and the building type and structure system are more varied. The structure design of high-rise buildings has become the main focus and difficult point. Therefore, it is almost impossible to implement full-scale experiments.

For the reasons given above, one analysis method based on the SIMUSHIS composed of modeling, solving and showing, is used to simulate the earthquake response of a high-raise structure [2].

This analysis consists of two parts:(1) to research the static response such as internal force, stress and strain of the structure as the seismic load is treated as equivalent static force; (2) to research the dynamic response such as displacement, velocity and acceleration of the structure under the random earthquake load and to research characteristics of motion of the structure.

\section{Analysis of Earthquake Response of Structure}

It can be very convenient for modeling and post-processing in ANSYS. In this paper, command streams in an interactive interface of the ANSYS are used for model building and one frame-tub structure will be simulated.

Dynamic Characteristics of Reinforced Concrete Frame-Tub Structures. Due to the nonlinear response the dynamic characteristics of the reinforced concrete frame-tub structure change 
with time. Therefore, the characteristic parameters are functions in relationship to time in the equations of motion. The differential equations of motion of multi-degree of freedom system can be put into matrix form as follow $[3,4]$ :

$$
[M]\{\Delta \ddot{x}(t)\}+[C(t)]\{\Delta \dot{x}(t)\}+[K(t)]\{\Delta(t)\}=\{\Delta p(t)\} \text {. }
$$

Where $M, C(t)$ and $K(t)$ indicate the mass, damping and stiffness matrix respectively, $\Delta \ddot{x}(t), \Delta \dot{x}(t)$ and $\Delta x(t)$ indicate vectors of the acceleration, velocity and displacement increment respectively, and $\Delta p(t)$ indicates the vector of equivalent earthquake force increment.

In Eq.1, $C(t)$ is modeled as Rayleigh damping which is proportional to mass and stiffness and can be calculated by the follow formula:

$$
[C(t)]=\alpha[M]+\beta[K(t)]
$$

In Eq.2, the scale factors $\alpha$ and $\beta$ are determined by two frequencies $\omega_{i}$ and $\omega_{j}$ and corresponding damping ratios $\xi_{i}$ and $\xi_{j}$ in Eq.3. Where $\xi_{i}$ and $\xi_{j}$ are approximately equal to 0.02 .

$$
\alpha=\frac{2\left(\xi_{i} \omega_{j}-\xi_{j} \omega_{i}\right) \omega_{i} \omega_{j}}{\omega_{j}^{2}-\omega_{i}^{2}}, \beta=\frac{2\left(\xi_{j} \omega_{j}-\xi_{i} \omega_{i}\right)}{\omega_{j}^{2}-\omega_{i}^{2}} .
$$

By means of step-by-step integration method, in every time interval $\Delta t$, the earthquake response of the structures can be solved from Eq.1.

Simplification of the Structural Model. An 18-story frame-tub structure, which is $54 \mathrm{~m}$ high, $44 \mathrm{~m}$ long and $16 \mathrm{~m}$ wide as shown in Fig.1, is selected. The site soil in the reservoir area belongs to hard clay and the construction site is classified in category II. Each layer is $3 \mathrm{~m}$ tall and the bay spacing is $12 \mathrm{~m}$. For computational convenience, the gravity density is valued at uniform $2700 \mathrm{~kg} / \mathrm{m}^{3}$ and the Poisson's ratio is equal to 0.2. All the model parameters are shown in Table 1.

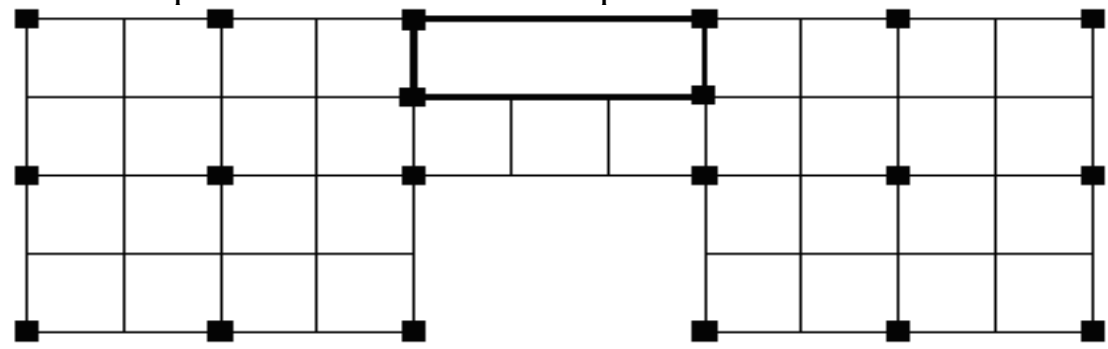

Fig.1 Structural plane layout

Table 1 Model parameters of structure

\begin{tabular}{|l|c|c|c|}
\hline Frame member & Sectional dimension[m] & Concrete grade & Elastic modulus [Mpa] \\
\hline Column & $1.1 \times 1.1$ & $\mathrm{C} 40$ & $3.25 \mathrm{e} 10$ \\
\hline Inner beam & $0.5 \times 0.8$ & $\mathrm{C} 40$ & $3.25 \mathrm{e} 10$ \\
\hline Secondary beam & $0.3 \times 0.5$ & $\mathrm{C} 40$ & $3.25 \mathrm{e} 10$ \\
\hline Shear wall & 0.3 & $\mathrm{C} 40$ & $3.25 \mathrm{e} 10$ \\
\hline Roof and floor plate & 0.2 & $\mathrm{C} 30$ & $3.0 \mathrm{e} 10$ \\
\hline Exterior wall & 0.2 & $\mathrm{C} 30$ & $3.0 \mathrm{e} 10$ \\
\hline
\end{tabular}

The frame in this paper is adopted for an interlaminar shear model and the mass of each layer is treated as a lumped mass with frame columns connecting the mass points. In this way, the structure can be modeled as a series multi-degree of freedom vibration system with lumped masses and its stiffness matrix is a band matrix.

Model Establishment and Computational Analysis. Because the cementation and slippage between steel bars and concrete have little effect on the dynamic characteristics of the overall structure, distributed models are adopted for elements [4,5].

BEAM188 is utilized for the beam and pillar units whose each node has six degrees of freedom including translational motions along the $\mathrm{X}$-axis, $\mathrm{Y}$-axis and $\mathrm{Z}$-axis and rotating motions around the three axes not considering buckling of cross section. SHELL63 is adopted for the roof and floor plate, exterior wall and shear wall units and the thickness of the plate unit is determinated by the principle of 
equal section area.

Loads and boundary conditions are applied to the model. For the convenience of comparison, a rigid- foundation is firstly adopted assuming that the rigid connection exists between the bottom of the structure and the foundation. That is to say, all the degrees of freedom of the bottom nodes are closed and limited to zero.

Here a subspace method is applied to model analysis, and a correctional EI Centro(N-S) seismic wave, the peak value of the acceleration-time history curve shown in Fig. 2 being 70gal,is input into the model in the interactive interface of the ANSYS Workbench. Then the first 5 modes of vibration whose natural frequencies are shown in Table 2 are extracted.

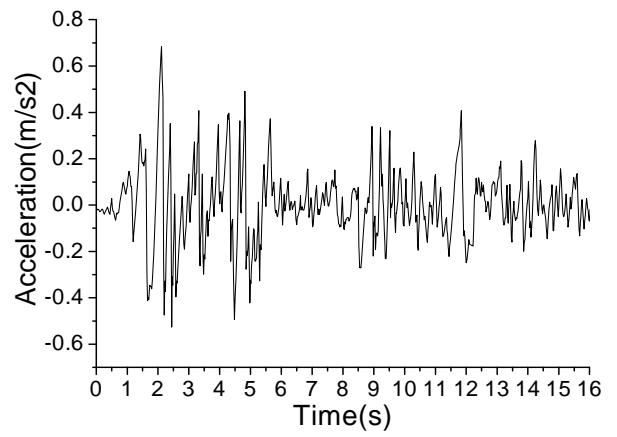

Fig.2 Acceleration-time history curve (70gal)

Table 2 Natural frequencies of structure based on rigid-foundation

\begin{tabular}{|c|c|c|c|c|c|}
\hline Mode of vibration & No.1 & No.2 & No.3 & No.4 & No.5 \\
\hline Natural frequency [Hz] & 0.38 & 0.72 & 1.03 & 1.24 & 1.40 \\
\hline
\end{tabular}

Dynamic Response and Time History Curves of Structure Based on Rigid-Foundation. Because of the limitation of space, only the time history curves of the 18th floor are listed as shown in Fig.3-Fig.6.

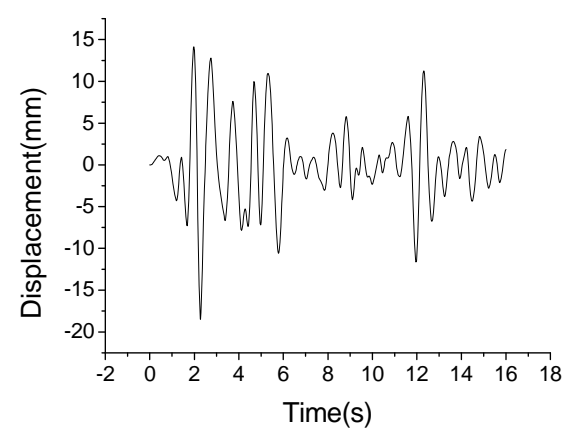

Fig.3 Displacement relative to ground

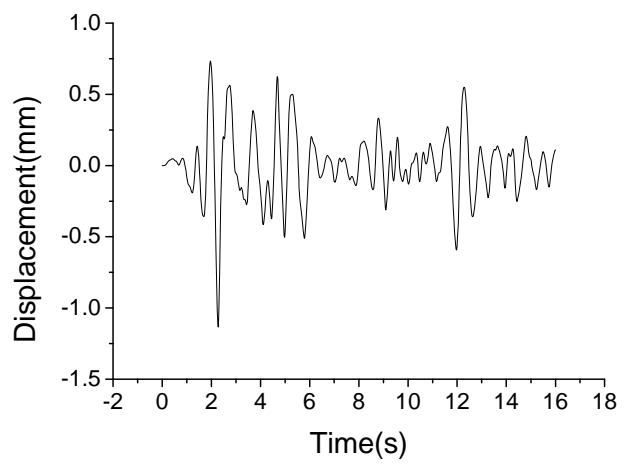

Fig.5 Relative storey displacement

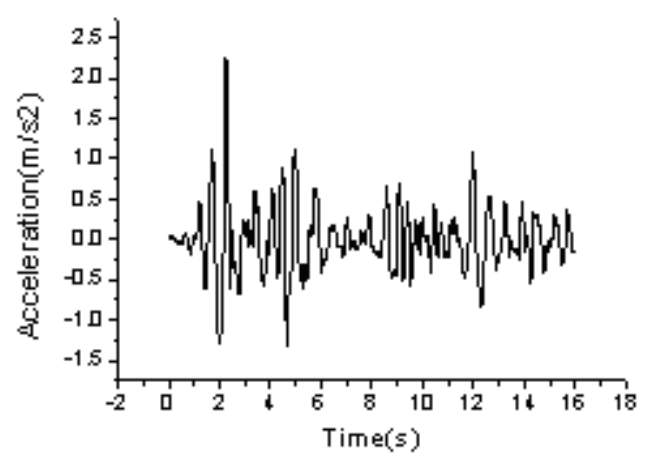

Fig.4 Absolute acceleration

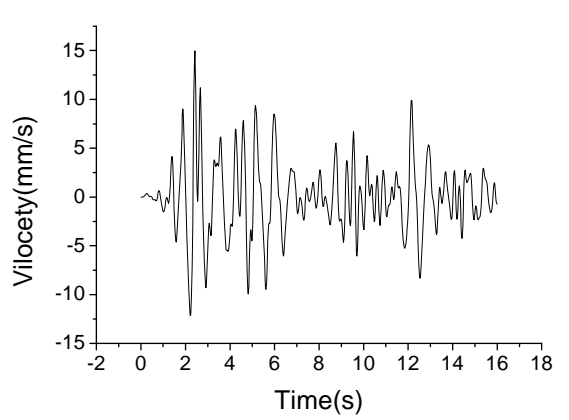

Fig.6 Relative storey velocity

\section{Summary}

By means of the ST based on the SIMUSHIS, the results of the analysis agree with the engineering 
practice. It is shown that the mode of horizontal vibration is dominant. Concretely, the first order vibration mode is a translational motion along the $\mathrm{Y}$-axis, the second mode is a rotating motion around the $\mathrm{Z}$-axis, the third mode is also a rotating motion around the $\mathrm{Z}$-axis, the fourth mode is a translational motion along the $\mathrm{X}$-axis and the fifth mode is torsion and bending coupled vibration.

\section{Acknowledgement}

The work reported in this paper was supported by "Liaoning BaiQianWan Talents Program" Fund (2010921077), Liaoning Provincial Educational Department Fund (L2010412), Liaoning Provincial Educational Department Fund (L2010411), Shenyang Science and Technology Plan Fund (F10-205-1-08). The supports are gratefully acknowledged.

\section{References}

[1] X.Z.Lu, J.J.Jiang, Simulation for the Collapse of WTC after Aeroplane Impact, China Civil Engineering Journal, Vol.34,No.6 (2001): p.8-10.

[2] W.Y.Wu, S.G.Zhang, Research on Multimedia Simulation Environment for Wind-induced Tall Building, Engineering Mechanics, Vol.14,No.4 (1997): p.121-127.

[3] Q.Ni, J.X.Tang, Application of Virtual Reality Technique to Dynamic Analysis of Building Structure, Microcomputer \& Its Applications, Vol.5 (1998): p.9-14

[4] Rajinder Bhasin, Amir M.Kaynia,Static and Dynamic Simulation of A 700-M High Rock Slope in Western Norway. Engineering Geology, Vol.71 (2004): p.213-226

[5] H.Wei, H.Z.Du, H.Z.Piao, H.S.Wu, Earthquake Resistant Behaviour of Concrete-filled Steel Tube Columns, Journal of Shenyang University of Technology, Vol.30,No.2 (2008): p.223-227. 